SABER POPULAR E

\section{SABER ACADÊMICO EM}

\section{DIÁLOGO NA EXTENSÃO:}

RELATOS DE UMA EXPERIÊNCIA

\author{
Maria Cláudia Bachion Ceribeli [*] \\ Harrison Bachion Ceribeli [**]
}

[*] Mestrado em Letras na área de concentração dos

Estudos Literários, pela Universidade Federal do Espírito Santo (UFES, 2019). Professora efetiva de Arte no Instituto Federal do Espírito Santo (IFES) e coordenadora do Núcleo de Arte e Cultura do Campus Piúma. ORCID: https://orcid.org/0000-0001-8764-7111 E-mail: claudiabachion@gmail.com

[**] Doutor em Ciências pelo Programa de Administração de Organizações da Universidade de São Paulo (FEARP/USP). Professor Adjunto da Universidade Federal de Ouro Preto, Instituto de Ciências Sociais Aplicadas, Departamento de Ciências Administrativas. ORCID: https://orcid.org/0000-0002-1654-6273

E-mail: harrisonbceribeli@hotmail.com

\section{RESUMO}

Para iniciar uma atividade de extensão é necessário olhar o entorno, observar os costumes da comunidade, as atividades ali realizadas e a sua cultura. Desse modo, percebe-se a riqueza envolvida nesse reduto. Alguns aspectos foram considerados para a execução deste projeto, como a aquisição de conhecimento nas próprias experiências, nas atividades aperfeiçoadas pela prática do dia a dia, reforçando a necessidade de se ouvir cada indivíduo para aprender, como também para compartilhar todo o saber adquirido. O projeto de extensão "IFES Pescador de Saberes" objetivou aproximar a Instituição e a comunidade do entorno do Campus Piúma para compartilhar saberes diversos contidos nos conhecimentos dessa comunidade, a fim de promover educação, respeito pelos saberes populares, formação diversificada, valorização da cultura local e bom relacionamento interpessoal, discutir valores e práticas, além de desenvolver conhecimentos em várias áreas advindas das vivências das pessoas da comunidade externa do Instituto $\mathrm{e}$ da própria prática educacional da Instituição.

Palavras-chave: Extensão. Saber popular e saber acadêmico. Diálogo de saberes. 


\section{INTRODUÇÃO}

A experiência de que trata este artigo, denominada Projeto "IFES Pescador de Saberes", ocorreu mensalmente, em encontros que duravam, aproximadamente, duas horas, com os moradores da comunidade de Piúma, Município no Litoral Sul do Estado do Espírito Santo. Nesses encontros, foram convidados músicos, bailarinos, historiadores, pesquisadores, pescadores, artesãos, ou seja, pessoas que tinham conhecimento sobre uma prática que acrescentasse saber em área de interesse dos moradores da comunidade, para partilharem seus saberes com os presentes.

Por meio de contatos com a comunidade, esses profissionais foram convidados para participarem do projeto, sendo então entrevistados. Eles vieram ao IFES-Campus Piúma, a fim de compartilharem suas experiências para uma educação de forma omnilateral, contribuindo para que este projeto se tornasse um caso de sucesso em extensão popular. Como Instituição Federal, de ensino público, o IFES tem um papel importante para a comunidade na qual está instalado, de forma a contribuir com a formação dos sujeitos para o desenvolvimento local e as atividades de extensão são realizadas para levar à comunidade os projetos, as pesquisas, as atividades que as pessoas no entorno da Instituição desejam, que necessitam para melhorar as condições sociais locais. Não se faz extensão sem a participação da comunidade.

Nesses encontros, foi possível aprender muito em áreas diferentes, além de conhecer as dificuldades e as histórias da realidade local. Algo muito importante pairou nos encontros: a alegria dos entrevistados por serem ouvidos e valorizados. O sentimento de realização por ter criado essa oportunidade de conviver com tanta gente, com tanta diversidade e com tanta riqueza de experiências para serem compartilhadas com outras pessoas acompanhava as manifestações de aprovação dos convidados da comunidade. Constata-se que aprender junto proporciona um entrelaçamento entre os conteúdos, o grupo, o meio e a sociedade, em suma, requer o diálogo com o outro.

Após as entrevistas dos convidados e o relato da atividade em discussão, a palavra era aberta ao público, que podia interagir com o expositor, em uma troca interessante de saberes. No decorrer dos relatos de experiências, os convidados encontravam eco naqueles que os ouviam, porque muitos se reconheciam neles, por fazerem parte do mesmo grupo. 


\section{O PROJETO IFES PESCADOR DE SABERES E SUA FUNDAMENTAÇÃO TEÓRICA}

O projeto iniciou em 2016. Para desenvolvê-lo, um edital da Pró-Reitoria de Extensão do IFES permitiu que uma bolsista (PAEX/PROEX) fosse contratada e colaborasse para o registro das atividades e na transcrição das entrevistas, pois tudo foi filmado, gravado, fotografado, para, em oportunidade posterior, ser transformado em livro sobre os saberes populares e os saberes acadêmicos da comunidade piumense. Os vídeos das entrevistas estão disponíveis, na íntegra, no Youtube.

Como afirma Antônio Candido, "o ponto de vista preponderante nos estudos filosóficos e sociais quase até os nossos dias foi, para usar uma expressão corriqueira, o do adulto, branco, civilizado, que reduz à sua própria realidade a realidade dos outros” (CANDIDO, 2000, p. 37), que não pode ser absoluto e, através do diálogo com os saberes populares, pode-se ter outro ponto de vista sobre as teorias praticamente restritas aos muros e bibliotecas das Instituições.

O projeto também faz homenagem às pessoas de mais idade, mais experientes, mais vividas, lembrando que o respeito aos idosos é sempre importante, por representarem a escola prática da vida. Com as suas próprias experiências, eles mostram como melhoraram os seus fazeres, ou seja, nos ensinam os seus saberes aperfeiçoados ao longo de suas trajetórias de vida. Essas pessoas mais experientes vão desenvolvendo as suas práticas de modos diversos, de forma que atendam às suas necessidades, geralmente antes que as Instituições de ensino cheguem até elas.

Vale enfatizar que os textos foram transcritos com a linguagem coloquial, simples, de uma roda de conversa e, portanto, foram mantidos os termos, os vícios de linguagem, todos sem as correções que um texto baseado apenas no modelo acadêmico exigiria; afinal, é um diálogo de saberes, não uma sobreposição deles. Freire (1987) alerta para a situação de opressão que se instaura quando não se estabelece esse diálogo, visto que o oprimido, no caso as pessoas da comunidade, é invadido pela cultura dominante, que não permite a sua libertação por meio de uma práxis que desconsidera os interesses, a história e a cultura que fazem parte da comunidade.

O IFES é uma Instituição Federal Pública que deve atuar em três eixos: o ensino, a pesquisa e a extensão, assim como as Universidades. Para atender às necessidades da comunidade, é necessário ir ao seu encontro para que, num processo dialógico e dialético, a instituição e a comunidade possam ampliar conhecimentos sobre a cultura local, a respeito de 
atividades artesanais, realizadas pelas pessoas da comunidade, associando-os aos conhecimentos científicos, numa busca por integração entre os saberes e numa atitude críticoreflexiva sobre eles.

Nesse caso, observou-se que as entrevistas realizadas durante a execução do projeto contribuem com o ensino, visto que os entrevistados trazem consigo um potencial educativo baseado em suas práticas cotidianas, aperfeiçoadas durante anos de experiência. A comunidade onde o IFES-Campus Piúma se localiza tem a pesca como atividade econômica principal, por essa razão, a maioria das entrevistas versou sobre a prática pesqueira e suas implicações ambientais, econômicas e culturais. O conteúdo das entrevistas trazia à luz relatos que surpreendiam pela consciência ambiental, preocupação com a manutenção dos recursos pesqueiros e a necessidade de atuação da Instituição para melhorar as condições da prática da atividade, formando profissionais habilitados para atuarem de forma técnica e capacitada, contribuindo para aperfeiçoar o processo da atividade pesqueira.

O Projeto "IFES Pescador de Saberes" abordou temas que estão relacionados à cultura local, aos cursos técnicos ofertados no Campus, à preservação ambiental, entre outros, promovendo a aproximação entre a instituição e a comunidade, e a troca de conhecimentos. A aprendizagem significativa ocorre mais naturalmente quando os conteúdos abordados são relacionados ao cotidiano do aluno, passando a fazer sentido. Ao contrário do ensino compartimentalizado e descontextualizado que, na maioria das vezes, não é compreendido pelo educando, que não sabe por que precisa conhecer certa informação e em que situação ela servirá à sua formação.

Sobre essa perspectiva, como indaga Freire (1996), por que não se aproveitam as experiências que os alunos trazem de viverem em áreas da cidade descuidadas pelo poder público, a poluição dos rios e outros locais, os lixões e os riscos que oferecem à saúde pública e ao meio ambiente (KLEIN; PÁTARO, 2008), a violência com a qual convivem, estabelecendo relação entre sua experiência social e os saberes curriculares, discutindo a desigualdade social? Assim, o projeto, além de extensão, relaciona as áreas abordadas nas entrevistas à realidade com a qual os discentes convivem. Além disso, é a democratização e o acesso ao conhecimento que se almeja quando a Instituição vai ao encontro da comunidade.

Quando se investiga o significado de democratizar no dicionário, encontra-se, entre outros, que algo se torna popular, ao alcance do povo, da maioria da população. A educação 
por assim dizer, torna-se democrática, mas isso não significa que alcança a todos que adentram em um ambiente educativo.

[...] quando temos em mente o desenvolvimento da democracia e a efetivação da cidadania, pensamos em uma escola que forme nossos jovens orientados para a participação social e respaldados por valores como tolerância, equidade, justiça social. Para fazê-lo de forma coerente com a democracia, entendemos que a educação deve pautar-se por certos princípios e ações que traduzam o ideal buscado. Por outro lado, a concretização dos ideais democráticos depende da educação, como uma medida que visa a igualdade de oportunidades. Sem educação extensiva a todos, a democracia não se realiza. A escola, enquanto instituição social, deve ser democrática, tanto em suas práticas quanto em seu acesso. Assim, não pode haver democratização do ensino sem esforços sistemáticos para o acesso e a permanência de todos na escola. $\mathrm{O}$ acesso reivindicado não é apenas de frequentar uma escola, mas sim o acesso aos bens culturais da sociedade: conhecimentos, linguagens, expressões artísticas, práticas sociais e morais, enfim, o direito a um legado de realizações históricas às quais conferimos valor e das quais esperamos que as novas gerações se apoderem (KLEIN; PÁTARO, 2008, p. 4).

Como se observa nas palavras de Klein e Pátaro (2008), pretende-se que os saberes desenvolvidos na instituição escolar e acadêmica sejam disponibilizados aos sujeitos e, mais que isso, que os saberes populares sejam aproveitados na formação dos discentes. Com a realização de um projeto de extensão popular, valores que formam um cidadão são desenvolvidos na convivência entre docentes, discentes e comunidade: empatia, respeito, solidariedade, educação.

Paulo Freire (1988) destaca a relação entre a escola e a vida. O autor enfatiza o educando como sujeito da história e acredita que as pessoas podem não ser letradas, mas todas pertencem a uma cultura e, que, quando o educador estabelece contato com a cultura dos alunos, ocorre o diálogo necessário para que novos conhecimentos sejam construídos. Freire acredita que quando se vê como produtor de cultura, o homem se entende como sujeito e não como objeto da aprendizagem. Isso implica em que o aluno, ao participar de um projeto de extensão, passa a ter papel ativo na construção de saberes e na solução de situações que dificultam a vida da comunidade, utilizando o conhecimento adquirido para desenvolver tais soluções.

O ideal do Projeto "IFES Pescador de Saberes" tem como base o texto de Boaventura de Souza Santos (2007). O autor trata das monoculturas, das ausências criadas por elas, como também das ecologias que podem corrigir essas ausências. Em relação às monoculturas (monocultura do saber, por exemplo, que ignora outros saberes que não o científico), explica 
Santos (2007), vêm produzindo ausências que dificultam a transformação da sociedade, porque ignoram outras fontes de conhecimento. Ignorar causa a ausência do que foi ignorado. Os saberes externos ao acadêmico são vistos como não existentes.

O projeto fundamentou-se na ecologia dos saberes, que, segundo Santos (2007), visa corrigir ausências promovidas pela prática de monoculturas. Para ele, as monoculturas produtoras das ausências são cinco, porém, neste projeto, foram abordadas três, devido à relação com o objetivo deste estudo:

1-Monocultura do saber e do rigor - produz ausência pela ignorância, por descredibilizar os povos, os grupos sociais, porque o único saber rigoroso seria o saber científico (de acordo com a ciência ocidental), causando a morte de conhecimentos alternativos (provindo de indígenas, camponeses, populares e urbanos).

Para corrigir esse tipo de ausência, o projeto integra o saber popular ao saber científico relacionado diretamente ao IFES-Campus Piúma, instalado na antiga Escola de Pesca, oferecendo cursos técnicos integrados ao ensino médio na área de pesca e de aquicultura e um curso superior de engenharia de pesca. A comunidade, que vive principalmente de recursos pesqueiros, vinha realizando as atividades de forma artesanal, o que ainda ocorre no caso dos pescadores e dos maricultores, ou seja, tinha desenvolvido um saber, um conhecimento, por meio de suas práticas.

Pretendeu-se, com esse projeto, promover a troca e a valorização dos saberes populares (citados no parágrafo anterior) e saber acadêmico, de forma a aproximar o Instituto e a Comunidade, e melhorar o processo ensino-aprendizagem, pelo estreitamento das relações entre teoria e prática, família-discente-docentes-Ifes. Ansiou-se também, por meio desta troca, contribuir com as atividades de pesquisa e de extensão do Campus Piúma, promovendo reflexões sobre conservação ambiental, sustentabilidade nas práticas pesqueiras e valorização dos indivíduos.

2-Monocultura da escala dominante - nesse caso, a ausência é criada pelo "particular e o local, que não conta, que é invisível, descartável, desprezível” (SANTOS, 2007, p. 31), porque só o que tem caráter universal é válido, independentemente de seu contexto. Por meio deste projeto, almejou-se dar valor ao local, ao particular. A cidade de Piúma é pequena, fora do eixo hegemônico, portanto, muito conhecimento que é produzido aqui não é conhecido ou 
valorizado, devido a esse tipo de monocultura.

3-Monocultura do produtivismo capitalista (SANTOS, 2007, p. 31) - produz ausência pela ideia de que tudo o que não é produtivo é estéril. A ausência é produzida pela improdutividade. A produtividade e o crescimento econômico é que contam. A comunidade não quer ser improdutiva, ao contrário, mas isso não significa acompanhar o pensamento capitalista predatório.

Este projeto objetivou contribuir na promoção da conservação do meio ambiente e dos recursos pesqueiros, visto que, devido ao pensamento e práticas predatórias, as espécies marinhas não são preservadas ou respeitadas durante sua fase de reprodução, havendo um grande impacto ambiental tanto pela pesca indevida quanto pelo grande número de turistas que chega à cidade, gerando, assim, maior volume de pesca e dos descartes indevidos de lixo. $\mathrm{O}$ peso do capitalismo sobre a forma como a sociedade consome e promove seu crescimento é bastante criticada por Adorno nos aforismos de Mínima Moralia (1944-1945), que aborda também a desconsideração com o ser humano, coisificado num mundo onde apenas o valor financeiro é observado nas atividades realizadas (ADORNO, 1993).

A “ausência é um desperdício de experiência", afirma Santos (2007, p. 32). Portanto, com este projeto pretendeu-se corrigir tais ausências, aproveitando o conhecimento da comunidade e promovendo o diálogo com o saber científico com vistas à melhora da vida da comunidade piumense e de outras que sigam a mesma linha de estudo.

As experiências e vivências das pessoas jovens, adultas e idosas da comunidade, o conhecimento anterior adquirido durante a vida desses indivíduos precisa ser levado em consideração, compartilhado e ampliado, para que possa servir como exemplo de motivação e de base para novos saberes, de ampliação do conhecimento, de possibilidade de aproveitamento em desenvolvimento de novas tecnologias e de aproximação e valorização da comunidade e da Instituição.

Por meio dos relatos desses detentores de conhecimentos e de suas práticas anteriores, durante a convivência da execução do projeto, procurou-se a valorização e o respeito dos conhecimentos anteriores e externos ao Ifes, em uma troca de saberes que contribuísse para o desenvolvimento da comunidade e do processo educacional do Instituto, integrando comunidade e Ifes.

Santos (2007, p. 20) cita que hoje existe "uma discrepância entre teoria e prática social 
que é nociva para a teoria e também para a prática". Ainda afirma que "para uma teoria cega, a prática social é invisível; para uma prática cega, a teoria social é irrelevante" (SANTOS, 2007, p. 20). Essa seria uma das razões do distanciamento entre as Universidades (teoria) e a prática (campo de aplicação do conhecimento acadêmico). Ainda nessa perspectiva, o autor escreve que as monoculturas vêm produzindo ausências que dificultam a transformação da sociedade, porque ignoram outras fontes de conhecimento, o que denomina de "epistemicídio" (SANTOS, 2007, p. 29).

Para modificar o quadro das ausências, reinventar a teoria crítica e promover a emancipação social, a "Sociologia das Ausências" demonstra que o "que não existe" é produzido como "não-existente" (SANTOS, 2007, p. 28), dando origem à razão indolente, que é preguiçosa, considera-se única, exclusiva e não percebe a riqueza inesgotável do mundo. Dessa forma, este projeto teve por objetivo criar meios para aproximar o saber acadêmico e cientifico do saber popular da comunidade, estabelecendo um diálogo entre os indivíduos, em que haja uma troca que beneficie a teoria científica e a prática diária.

Santos (2007), para combater as monoculturas, propõe adotar cinco ecologias:

1- Ecologia dos saberes - em que ocorre o "diálogo do saber científico com o saber popular e laico" (FRIGOTTO, 2007, p. 9). Esse é o objeto com o qual este projeto se ocupou, quando propôs o diálogo entre o IFES-Campus Piúma e a comunidade piumense, especialmente os pescadores, marisqueiras, artesãos, representantes de atividades culturais tradicionais, pessoas mais antigas da comunidade, e comunidade escolar e acadêmica.

2- Ecologia das temporalidades - que leva em consideração "diferentes e contraditórios tempos históricos" (FRIGOTTO, 2007, p. 9), não apenas aquele que dá prioridade aos países desenvolvidos, estabelecendo uma práxis com modelo pronto e que, caso outros não sigam, não são considerados críveis.

3- Ecologia do reconhecimento - que supera as hierarquias para perceber o que cada um pode oferecer.

4- Ecologia da transescala - a valorização ultrapassa o que é apenas de caráter universal, articulando projetos locais e nacionais também. Essa é uma ecologia que embasou este estudo. De acordo com o autor, as "experiências muito locais, nem muito conhecidas, nem legitimadas pelas ciências sociais hegemônicas, são hostilizadas pelos meios de 
comunicação social, e por isso têm permanecido invisíveis, desacreditadas" (SANTOS, 2007, p. 23). Antes do IFES ser instalado, já havia indivíduos realizando atividades, que detinham experiências e conhecimentos que lhes davam meios de produzir e viver. Foi objetivo deste projeto valorizar, tornar visíveis esses conhecimentos e práticas.

5- Ecologia das produtividades - "valorização de sistemas alternativos de produção, que sejam da economia solidária" (FRIGOTTO, 2007, p. 9) ou de outras formas, e não apenas o modelo capitalista de exploração.

Como destaca o texto dos Parâmetros Curriculares Nacionais,

[...] toda experiência construída no passado deve ser analisada, em busca das relações que estabelece com o presente e o devir. Partilhar o conhecimento socialmente instituído, aquilo que foi herdado do passado, é apenas o começo do reconhecimento da parte que cabe a cada um no processo histórico, o dado. $\mathrm{O}$ conhecimento que pode parecer, em um primeiro momento, como imediato, tem por trás de si uma história de lutas classificatórias que devem ser revistas no âmbito escolar (Brasil, 2000, pág. 7).

É objetivo do IFES e da Universidade estabelecer contato entre a comunidade e as Instituições, de modo a atender às demandas dessa comunidade, pois, ao trabalhar com relatos de conhecimentos e de experiências das pessoas da comunidade, procura-se a valorização dessas pessoas, de seus saberes externos e anteriores, desenvolvendo o respeito por esses conhecimentos e pelas pessoas mais experientes (idosas), como também possibilitando o desenvolvimento cultural dos indivíduos que participaram do projeto, além de ouvir sobre as demandas desses sujeitos. Convidando pessoas da própria comunidade para relatar suas experiências, lideranças detentoras de algum tipo de conhecimento, técnica, saber, advindo de suas próprias práticas, também foi desenvolvida a autoestima e a comunicação dos participantes.

A atividade do projeto está associada à área de linguagens e códigos, mas também às disciplinas da área técnica, já que os palestrantes foram pescadores, marisqueiras, artesãos, comerciantes, empresários, grupos de dança folclórica e servidores docentes do campus, que atuam nas disciplinas da área técnica, abordando as atividades desenvolvidas por eles. Houve dias em que os relatos contaram com a participação dos profissionais do IFES-Campus Piúma e de alunos dos cursos técnicos e do curso superior, o que possibilitou aos discentes refletir sobre as demandas levantadas pela comunidade nas atividades pesqueiras e como os aprendizados (que estão aprendendo ou ainda precisam aprender) podem colaborar para atender 
tais demandas.

Os assuntos abordados foram relacionados ao meio ambiente, boas práticas na área pesqueira, entre outros conhecimentos científicos, com a intenção de haver troca entre os saberes populares e acadêmicos. Assim sendo, cada encontro tratou de um tema. Para esses encontros, foram convidadas pessoas com conhecimento reconhecido pela comunidade para explanar sobre os temas propostos. Portanto, o texto construído durante a execução do projeto é o resultado de uma coletânea de saberes.

A proposta do projeto é inter e multidisciplinar, e, por meio da interação entre os saberes e a reflexão sobre as experiências, contribuir para promover a transformação do senso comum para a consciência filosófica, o que pode ser alcançado pela educação (SAVIANI, 1989). Essa educação, à qual Saviani (idem) se refere, é capaz de promover um processo que desconstrua paradigmas e concepções que estão instalados na ideologia dominante, construindo uma nova concepção sobre o mundo, em bases filosóficas (idem).

\section{EXECUÇÃO DO PROJETO: RESULTADOS E DISCUSSÃO}

A primeira entrevista foi sobre a História de Piúma, com Cristiano das Neves Bodart, atualmente professor na Universidade Federal de Alagoas. Em uma abordagem histórica e sociológica, Bodart narrou sobre a origem da cidade, de modo a proporcionar conhecimentos sobre o local, seu contexto e os fatores que contribuíram para seu desenvolvimento, as alterações na conformação geográfica, urbana e social. A partir de sua vasta fonte de informações, no Instituto Histórico e Geográfico de Piúma, do qual era Presidente na época, Bodart ressalta que é preciso conhecer para preservar. Ele destaca a questão da preservação ao trazer à tona as origens indígenas, incluindo sítios arqueológicos recém-descobertos na região.

O Instituto Histórico e Geográfico de Piúma (IHGP) foi o primeiro local de coleta de informações sobre temas e pessoas que faziam parte da comunidade, para fonte dos saberes a serem "pescados" durante o projeto. A região registra uma história que envolve colonização, Padre Anchieta, imigração e escravidão, que foi trazida ao conhecimento do público que estava presente, incluindo alunos do Instituto.

Cristiano Bodart foi convidado para o primeiro evento do Projeto "IFES Pescador de 
Saberes", devido ao fato de que o tema abordado "História de Piúma" possibilitava identificar as pesquisas que já vêm sendo realizadas sobre a História da cidade e as relações dessa História com os saberes populares de seus moradores, os quais são de grande valor. Tais saberes foram adquiridos por meio de suas práticas cotidianas, buscando superar suas dificuldades, descobrindo meios de irem aperfeiçoando e melhorando a execução e a condução de suas atividades em seus benefícios, de suas famílias e da comunidade na qual estão inseridos.

A segunda entrevista abordou o tema Território Sul Litorâneo. Para esse momento, foram convidadas Denize Mezadri de Almeida e Deise Thompson Lugão, ambas das redes municipal e estadual de educação, pesquisadoras nas áreas de ocupação do território, relações entre a urbanização e os reflexos para o meio ambiente, além das consequências para o desenvolvimento da cidade e da região, da exploração turística sem estrutura ou preocupação com a preservação ambiental.

O relato foi uma apresentação que contribuiu para o conhecimento dos danos causados ao meio ambiente da cidade e da região, além de conscientizar sobre os cuidados quanto à utilização do espaço e dos recursos naturais, destacando que, apesar dos professores trabalharem nas escolas o tema com seus alunos, ainda falta muito para que as ações do homem deixem de interferir predatoriamente na manutenção dos ecossistemas e na preservação ambiental.

A entrevista que se seguiu abordou o tema carpintaria naval, para a qual foram convidados os proprietários de um dos estaleiros da cidade, a família Jorades Miranda. Essa família é uma das mais tradicionais na construção naval em Piúma. O negócio é de tradição familiar, ou seja, os conhecimentos na construção naval passam de pai para filho, como ocorre com algumas atividades na cidade. Por essa razão, a família Jorades Miranda foi convidada para participar do Projeto "IFES Pescador de Saberes" para que o conhecimento que eles adquiriram, na sua trajetória profissional, com a própria prática, pudesse ser compartilhado.

Após relatar como funciona a construção no estaleiro, a reforma de barcos realizada também no estaleiro, a família apresentou questões para que a Instituição pudesse ajudar a resolver, como a destinação da serragem e dos restos da madeira descartados durante o trabalho, além de relatar os problemas que a poluição dos rios causa na realização do trabalho de recolhida ou de retorno à água de uma embarcação. 
A tecnologia, os conhecimentos adquiridos na Universidade, contribuíram para que o processo da construção naval fosse facilitado, o que revela o papel do saber acadêmico para a comunidade, que, por sua vez, leva às Instituições suas demandas, que, através da extensão, podem ser conhecidas e, por meio de pesquisas, solucionadas. Já os conhecimentos para a construção e manutenção das embarcações foram obtidos de forma autodidata pelo fundador do estaleiro e que vêm sendo passados de pai para filho.

Um fato que merece destaque nessa atividade familiar advém da dificuldade da mão de obra familiar no trabalho. A família relatou que, possivelmente, essa transmissão de saberes seja interrompida, porque os filhos, em contato com os saberes acadêmicos, não querem dar continuidade ao trabalho pesado da construção naval.

No entanto, todos eles relatam grande preocupação com a preservação ambiental, compreendendo os reflexos que a falta desses cuidados traz para seu próprio negócio. Identificase aqui uma questão problemática: a educação ofertada de pai para filho sendo interrompida. Dessa questão, surgem questionamentos, tais como: O que ocorre com esse saber popular? Essa transmissão familiar poderia ser substituída pela Academia?

No entanto, o cenário presente, na cidade e região, é caracterizado pela construção naval que segue a tradição do aprendizado familiar. Se o ciclo é interrompido, não existem cursos formais para assumir essa lacuna, segundo os relatos da família Jorades Miranda durante a entrevista. Não há uma formação nessa área nas escolas ou Instituições de ensino na região.

A entrevista sobre o histórico da Associação dos Maricultores de Piúma (AMPI) foi com o Presidente da Associação, Antônio Carlos Laurindo, e com o professor do IFES, Thiago Bernardo de Souza, que atua na área de ensino e pesquisas relacionadas à maricultura (na época em que o projeto foi realizado, o professor Thiago Bernardo de Souza atuava no Campus Piúma). Souza colaborou para a regularização da AMPI nas questões de organização de documentos e adotou a prática de convidar o Sr. Antônio Carlos Laurindo para participar das aulas com os alunos do Campus numa integração entre o saber popular e o saber acadêmico. Segundo o Sr. Antônio Carlos Laurindo, um aprende com o outro, o que reforça a necessidade do reconhecimento do saber popular e sua aproximação com o saber acadêmico.

Nessa entrevista, observou-se que o saber popular precisa ser considerado, porque, nesse caso, as condições de cultivo advindas da experiência do Sr. Antônio foram valiosas para a 
prática descrita de forma teórica. O relato abordou as dificuldades do trabalho com a maricultura, além da preocupação com o meio ambiente e da extração de recursos pesqueiros de forma que não faltem, porque, como foi apresentado, a extração de forma desordenada leva à extinção.

Observou-se que a comunidade espera esse apoio da Instituição, por meio da colaboração na superação das dificuldades e apresentando novas técnicas, para o desenvolvimento dos processos artesanais de produção. Nesse tipo de trabalho artesanal, o saber popular também é transmitido de pai para filho, mas o Sr. Antônio Laurindo reconheceu que, por meio da troca de saberes com o professor Thiago Bernardo, os procedimentos para o cultivo e a colheita dos mariscos foram aperfeiçoados.

Também fizeram parte dos registros das entrevistas a cultura, a música, as tradições e o artesanato da cidade. Estiveram presentes Leandro Berola, músico muito conhecido de Piúma e região, que representa bem a cultural local; e o grupo Pipoqueira, premiado várias vezes por apresentações tradicionais de quadrilha e outras danças. Berola compôs uma música intitulada “As gírias de Piúma” cujo repertório linguístico envolve a cultura local, além de cantar alguns sucessos de blocos de carnaval tradicionais. As letras das músicas são um registro da identidade cultural e linguística da cidade.

Trajados tipicamente, os membros do grupo Pipoqueira fizeram uma apresentação de danças de quadrilha. O grupo tinha uma história, fazia parte de um projeto desenvolvido por um professor da Rede Estadual, em um bairro com pessoas em situação de vulnerabilidade, que, graças a esse trabalho com a dança, permitia que jovens de idades diversas não estivessem nas ruas. Esse grupo dependia de recursos externos para comparecer a eventos, por isso relatou dificuldades para continuar participando de competições de quadrilha, já que os recursos estão escassos. 
FIGURA 1 - Foto: grupo Pipoqueira se apresentando para o Projeto "IFES Pescador de Saberes", no IFESCampus Piúma.

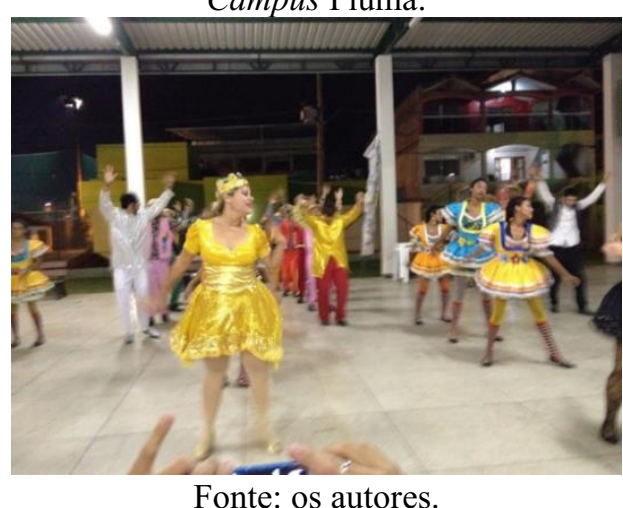

Para falar sobre o artesanato tradicional de Piúma - conhecida como a "Cidade das conchas" - confeccionado com conchas catadas em suas praias, foi convidada a Sra . Josephina Muniz Guimarães, filha de Dona Carmen, uma das pioneiras no artesanato em Piúma. Por meio do seu relato, foi possível perceber que, como atividade das mais tradicionais na cidade, muitas famílias sobreviviam desse comércio, mas, com o passar do tempo, o descuido com o meio ambiente resultou na escassez de alguns tipos de conchas, o que reduziu a matéria-prima do artesanato.

No decorrer da entrevista, a $\mathrm{Sr}^{\mathrm{a}}$. Josephina mostrou diversos materiais que fazem parte da história de sua mãe, como instrumentos utilizados na confecção do artesanato, livros sobre Dona Carmen, conchas que ela empregava, recortes de jornais com entrevistas sobre o trabalho realizado por essa pioneira do artesanato em conchas da cidade e região e também alguns objetos elaborados por ela, no seu período de produção, como flores, bonecos e animais. Como o papel da fotografia é abastecer a memória do passado, as fotos mostradas pela entrevistada documentam artesanatos que, caso não tivessem sido capturados nas imagens, seus regitros certamente não teriam ocorrido e estariam perdidos na história da cidade.

Se não fossem as memórias capturadas nas fotografias também não se teria como perceber as mudanças ocorridas nesse trabalho manual. Segundo a $\mathrm{Sr}^{\mathrm{a}}$. Josephina, a alteração na forma de realização das peças ocorreu na utilização de produtos, como tintas, que, no início, não faziam parte da produção, mantendo-se as conchas com as cores originais.

A exposição de objetos, textos jornalísticos, livros, fotos e artesanato em conchas foi também uma apresentação de acervo histórico de uma atividade que faz parte da construção da 
cidade, além de uma personagem, Dona Carmem, representante da história local, pela atividade artesanal que desenvolveu, significou e continua significando e representando a comunidade. Abaixo, algumas fotos dos trabalhos da Dona Carmen e dos materiais trazidos pela entrevistada da noite, sua filha, Josephina Muniz Guimarães e disponibilizados em exposição, durante a entrevista.

FIGURA 2 - Foto: peças do artesanato em conchas e ferramentas utilizadas por Dona Carmen, uma das pioneiras do artesanato em conchas de Piúma.

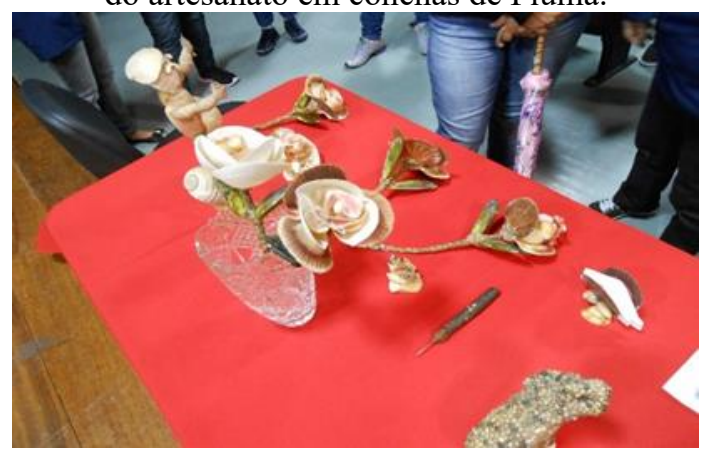

Fonte: os autores

FIGURA 3 - Fotos: em destaque flores feitas em conchas por Dona Carmen.

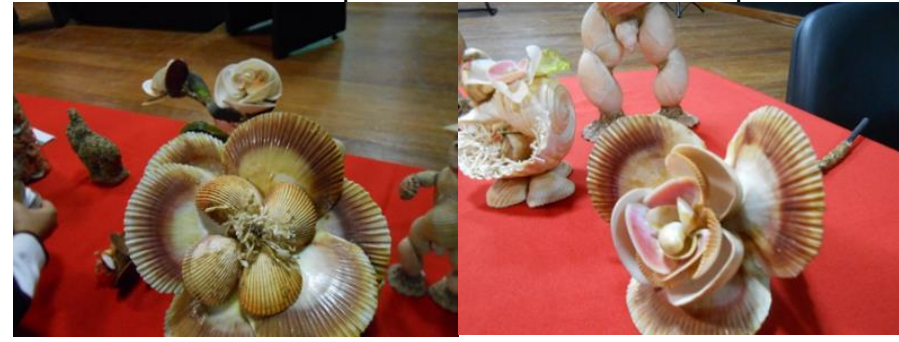

Fonte: os autores.

FIGURA 4 - Foto: bonecos conchabansa em destaque.

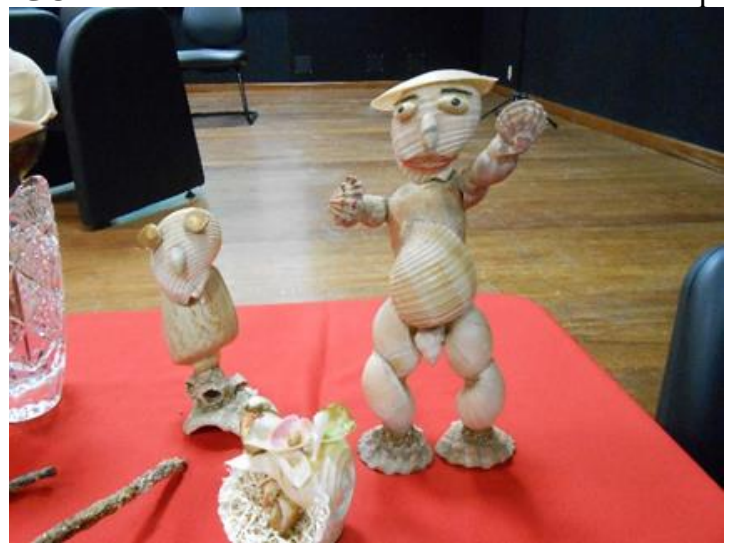

Fonte: os autores. 
Dando continuidade às entrevistas, foram convidados pescadores e comerciantes varejistas locais da atividade pesqueira que representam, economicamente, a fonte de renda de grande parte da população local e regional. Como uma das primeiras atividades realizadas pelo homem, a pesca, aqui na região, ainda se mantém artesanal e, pelos relatos, observou-se uma preocupação com a pesca sustentável, o cuidado com o meio ambiente e com o manuseio do pescado. Foi possível conhecer a cadeia de extração de peixe, desde a chegada nos pontos de venda até os cuidados que se têm e aqueles que se deveriam ter em todo o processo.

A experiência desses profissionais envolve muito conhecimento sobre as marés, as fases da lua, o tempo, a qualidade do pescado. Nesse momento de explanação de seus conhecimentos, sentiram-se valorizados por serem ouvidos. Esse sentimento de valorização para com esses profissionais é muito importante, por relatarem, inclusive, que são vistos, muitas vezes, de forma negativa pela sociedade, pela simplicidade com que vivem.

Para esse momento, foi preciso ganhar a confiança desses profissionais para aceitarem falar sobre suas vidas de pescador, seus saberes e a forma como comercializam sua produção. Por duas vezes, as entrevistas foram confirmadas e os entrevistados não compareceram ao ambiente acadêmico. Nesse caso, foi preciso comparecer ao porto de Piúma, em busca de pescadores que se dispusessem a ter uma conversa informal, em forma de entrevista, através da qual as experiências fossem compartilhadas. A maioria deles não quer que os filhos sigam na mesma profissão, pelas dificuldades que enfrentam, desde a saída com o barco, até o retorno com o produto da pesca. Dessa forma, os grandes barcos, tipo traineiras, que pescam grandes quantidades, e que, segundo eles, podem trazer prejuízos ao meio ambiente, vão ocupando os espaços do pescador artesanal.

Outra entrevista trouxe à discussão o comércio varejista de recursos pesqueiros na cidade. Foram três proprietários a discorrer sobre como se dá a compra e a venda do pescado em Piúma. A forma como esses comerciantes varejistas de pescado e os pescadores desenvolvem suas atividades é exemplo de solidariedade e cidadania. Respeitam-se e colaboram entre si. Foram muitos conhecimentos, muita sabedoria e tudo de forma simples, numa conversa que, para quem estava lá, com certeza foi um exemplo de vida. Os entrevistados demonstraram preocupação com o tipo de produtos que compram, de forma que a qualidade do pescado seja um aspecto sempre presente nas relações de compra e venda no comércio pesqueiro local. 
Através dos relatos, foi possível observar que, como quem vai consumir o pescado nem sempre conhece se o produto tem boa qualidade ou não, a honestidade e o conhecimento desses comerciantes podem significar a diferença entre comprar um produto saudável ou não. Portanto, mais uma vez se verifica a importância de observar e valorizar o saber popular.

Outra entrevista que se destacou em relação à cultura local, foi a de um grupo tradicional de senhoras idosas de Piúma, “As meninas". Algumas já morreram, devido à idade avançada, mas sempre chegam novas integrantes, por isso esse grupo não finda. Elas são chamadas para se apresentarem em ocasiões especiais na cidade. Relataram que é por meio das fotos e dos vídeos das entrevistas que concedem que aquelas que já se foram são imortalizadas.

FIGURA 5 - Foto: O grupo “As Meninas”, no auditório do IFES-Campus Piúma, participando do Projeto "IFES Pescador de Saberes".

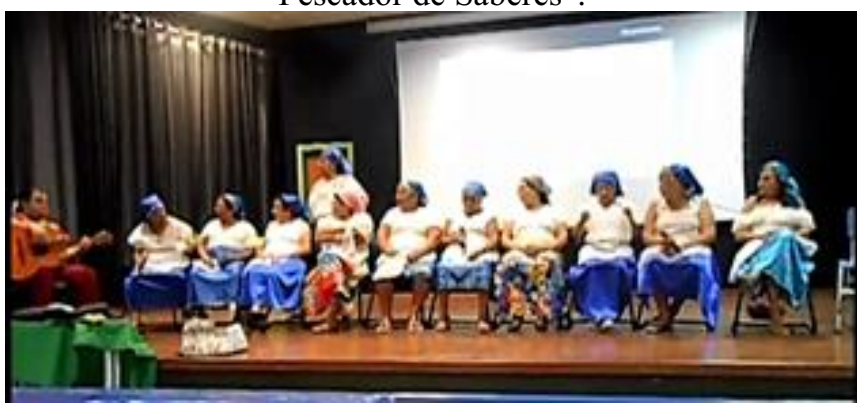

Fonte: os autores.

Como mostra o registro na figura 5, elas se sentem valorizadas, incluídas, respeitadas, porque, apesar da idade avançada, são convidadas para se apresentarem em eventos. Assim, mantêm-se vivas na história do Município de Piúma. O grupo “As meninas” apresentou canto e dança do repertório das festas de início e de final ano, encantando a todos com sua jovialidade, alegria e figurino.

Com os relatos, observou-se que elas fazem parte da história local e são quase folclóricas, visto estarem sempre em festividades tradicionais, com apresentações temáticas voltadas à necessidade de cada evento. São pessoas cujas famílias são conhecidas na região, pela ancestral ligação com a formação da cidade. Como sujeitos experientes, de idade mais avançada, representam repertório vivo da comunidade e, como tal, dignos de registro num projeto que pretende ser ligação da Instituição com a Comunidade. 


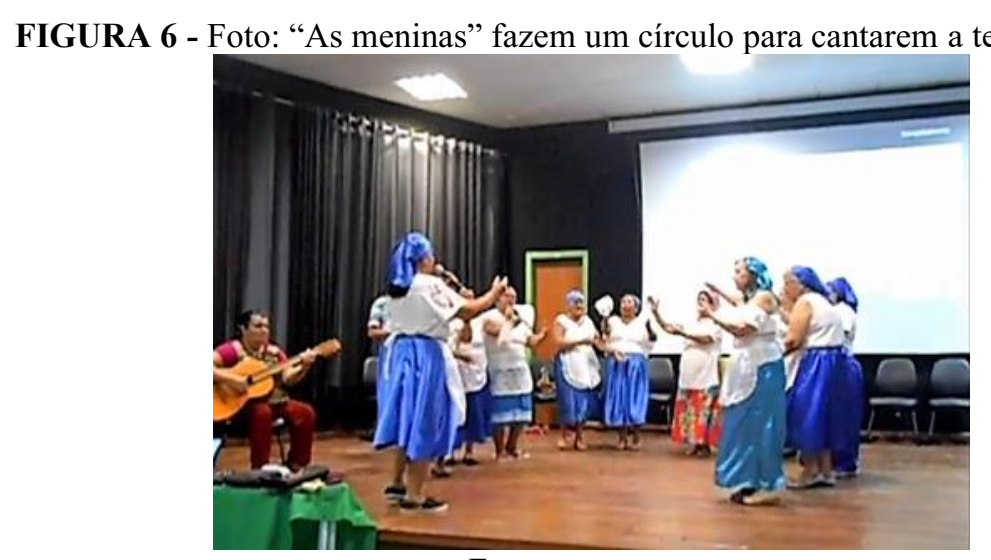

Fonte: os autores.

FIGURA 7 - Foto: “As meninas” fazem um círculo para cantarem a música da despedida, acenando seus lenços.

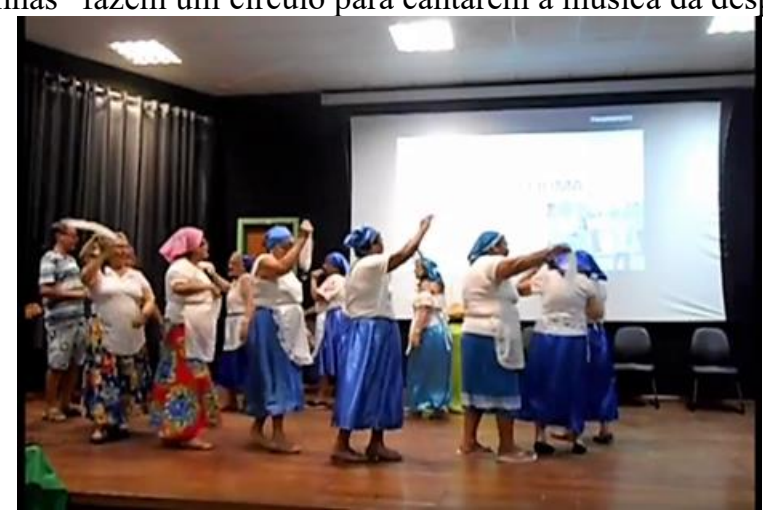

Fonte: os autores.

Para finalizar, a entrevista foi com profissionais relacionados aos cursos técnicos e à graduação ofertados pelo IFES-Campus Piúma. Como os cursos se referem à área da pesca e da aquicultura, foram convidados os engenheiros de pesca: Henrique David Lavander, Victor Hugo Silva e Silva, e Dayse Aline Silva Bartolomeu de Oliveira. O objetivo da entrevista foi esclarecer a comunidade sobre os benefícios dos cursos oferecidos pela Instituição, de forma que, encaminhando seus filhos para esses cursos, as atividades já desenvolvidas na cidade e região sejam feitas de forma cada vez mais eficiente e técnica, amparadas em pesquisas científicas que os profissionais da Instituição desenvolvem para aplicação nas práticas atualmente desenvolvidas.

Essa entrevista com os profisssionais relacionados aos cursos técnicos e à graduação ofertados pelo IFES-Campus Piúma foi relevante para informar aos futuros alunos que tipo de formação o Campus oferta e qual a aplicação dessa formação nas atividades pesqueiras 
realizadas na cidade e na região, e também em outros locais. Além das atividades de pesca e aquicultura, há indústrias de processamento de pescado na cidade que precisam de mão de obra qualificada para desempenhar as funções na linha de produção.

Visando contribuir com o aperfeiçoamento dessas atividades, o Campus promove cursos de formação para os pescadores, marisqueiras e para os filhos desses profissionais, objetivando facilitar e melhorar os processos que envolvem a realização dessas práticas. Deve-se considerar que o IFES-Campus Piúma foi criado com o eixo de recursos pesqueiros, porque Piúma e região possuem a pesca como uma das atividades principais da comunidade. E o Instituto foi implantado no local para promover o avanço e o desenvolvimento desse setor na cidade e na região.

\section{CONSIDERAÇÕES FINAIS}

O Projeto "IFES Pescador de Saberes" trouxe muito conhecimento a todos que participaram, promovendo o diálogo entre saber popular e saber acadêmico. Como o nome diz, a proposta foi sair pescando saberes na comunidade, que, como todo grupo de indivíduos, tem uma história, um desenvolvimento, um processo de formação e de crescimento. O resultado foi um conjunto de histórias, de memórias, de conhecimentos adquiridos na prática do ofício, e uma compreensão de que, só por meio do registro dessa história, dessa memória, pode-se preparar um futuro melhor para as próximas gerações e modificar o presente que nem sempre está sendo conduzido da melhor forma.

Observou-se que as pessoas mais experientes querem ser ouvidas, que seus saberes são muito importantes para se evitar erros já cometidos, e que não podem ser repetidos. É importante salientar que a comunidade local está interessada na conservação de seu espaço, preocupa-se com o meio ambiente. Essa preocupação não os impede de almejarem o crescimento, por terem em mente que preservação pode fluir com crescimento desde que este não se sobreponha àquela. O diálogo ainda é uma forma muito eficiente de conhecer o que a população espera de seus governantes, gestores, empresários, professores, e de todos os cidadãos que habitam um mesmo espaço. 
Neste projeto, ouvindo a comunidade, percebeu-se que as histórias de todos possuem em comum uma vida de muito trabalho, busca de melhores e mais sustentáveis práticas em seus ofícios, com respeito ao meio ambiente. A esperança no Instituto Federal e na Universidade como um local de pesquisa, conhecimento, desenvolvimento de pessoas e formação de cidadãos, com preparo para atuarem no mercado de trabalho, trazendo melhores condições de vida aos moradores das localidades onde atuam, além de auxiliarem na resolução de problemas que a comunidade enfrenta, proporcionando aos pais melhores condições de trabalho e oportunidades de trabalho para seus filhos, num processo de evolução progressiva para as gerações seguintes.

No caso de Piúma, no Espírito Santo, onde o projeto foi realizado, os moradores e professores entrevistados manifestam sua preocupação com a forma com que o turismo é explorado (especialmente na entrevista sobre Território Sul Litorâneo), com as práticas profissionais envolvendo a pesca, com a qualidade dos recursos pesqueiros, com a preparação dos profissionais para manipulação desses recursos, com a sustentabilidade e o meio ambiente, a destinação do que é descartado na construção de embarcações e no processamento do pescado. Os vídeos das entrevistas estão no canal do Youtube da autora, para conhecimento dos depoimentos na íntegra.

As fotos que ilustram o artigo foram tiradas durante as entrevistas, com consentimento dos participantes e não houve necessidade de submeter o projeto à análise de caráter ético, porque o respeito ao ser humano foi prioridade na realização das atividades, que também não incluíam a participação de animais.

Assim, avalia-se que este artigo, produzido a partir dos relatos da comunidade, concedidos em entrevistas e visitas in loco, é fonte de pesquisa para professores do IFES, da Universidade, historiadores, educadores, gestores públicos e pessoas que queiram conhecer sobre cultura, artesanato em conchas, música, aquicultura, pesca, comércio e indústria, construção naval, engenharia de pesca, história, Território Sul Litorâneo, meio ambiente, sustentabilidade e extensão universitária.

Para quem deseja fazer extensão, foi uma ótima experiência e um modo excelente de fazer novos amigos, além de aproximar a instituição da comunidade. Fica um convite a todos que trabalham em extensão, nos Institutos Federais e nas Universidades, para que também 'pesquem saberes' nas comunidades onde atuam. A troca, o ouvir outros saberes, que não os 
acadêmicos, é muito importante e enriquecedora. É respeitar o saber popular, como fonte de aprendizado, tão importante quanto o saber acadêmico.

\title{
REFERÊNCIAS
}

ADORNO, Theodor W. Minima moralia: reflexões a partir da vida danificada. Tradução de Artur Morão. Lisboa: Edições 70, 1993.

BRASIL. Ministério da Educação. Secretaria de Educação Média e Tecnológica. Parâmetros Curriculares Nacionais (Ensino Médio). Brasília: MEC, 2000.

CANDIDO, Antonio. Literatura e sociedade. $8^{\text {a }}$ ed. São Paulo: Publifolha, 2000.

FREIRE, Paulo. A importância do ato de ler: em três artigos que se completam. 22 ed. São Paulo: Cortez, 1988.

FREIRE, Paulo. Pedagogia da Autonomia. São Paulo: Paz e Terra, 1996.

FREIRE, Paulo. Pedagogia do oprimido.17ª ed. Rio de Janeiro: Paz e Terra, 1987.

FRIGOTTO, Gaudêncio. Apresentação. In: SANTOS, Boaventura de Sousa. Renovar a teoria crítica e reinventar a emancipação social. Tradução Mouzar Benedito. São Paulo: Boitempo, 2007.

KLEIN, A. M.; PÁTARO, C. S. O. A escola frente às novas demandas sociais: educação comunitária e formação para a cidadania. Revista Cordis, n. 1, p. 1-18, 2008.

SANTOS, Boaventura de Sousa. Renovar a teoria crítica e reinventar a emancipação social. Tradução Mouzar Benedito. São Paulo: Boitempo, 2007.

SAVIANI, Demerval. Educação: do senso comum à consciência filosófica. São Paulo: Cortez, 1989.

\section{POPULAR KNOWING AND ACADEMIC KNOWING IN DIALOGUE TO THE \\ EXTENSION: REPORTS FROM AN EXPERIENCE}

\begin{abstract}
To start an extension activity, it is necessary to look around, observe the customs of the community, the activities carried out there and its culture. In this way, we can see the wealth involved in this stronghold. Some aspects were considered for the execution of this project, such as the acquisition of knowledge in the experiences themselves, in the activities perfected by the daily practice, reinforcing the need to listen
\end{abstract}


to each individual to learn, as well as to share all the acquired knowledge. The "IFES Pescador de Saberes" extension project aimed to bring the Institution and the community close to the Campus Piúma to share diverse knowledge contained in the knowledge of this community, in order to promote education, respect for popular knowledge, diversified training, and appreciation of local culture and good interpersonal skills, discussing values and practices, in addition to developing knowledge in various areas arising from the experiences of people from the Institute's external community and from the Institution's own educational practice.

Keywords: Extension. Popular knowledge and academic knowledge. Knowledge dialogue.

\section{CONOCER A LA AMPLIACIÓN POPULAR Y ACADÉMICA DEL DIÁLOGO EN LA EXTENSIÓN: INFORMES DE UNA EXPERIENCIA}

\section{RESUMEN}

Para iniciar una actividad de extensión, es necesario mirar a su alrededor, observar las costumbres de la comunidad, las actividades que allí se realizan y su cultura. De esta manera, podemos ver la riqueza involucrada en esta fortaleza. Se consideraron algunos aspectos para la ejecución de este proyecto, como la adquisición de conocimientos en las propias experiencias, en las actividades perfeccionadas por la práctica diaria, reforzando la necesidad de escuchar a cada individuo para aprender, así como compartir todos los conocimientos adquiridos. El proyecto de extensión "IFES Pescador de Saberes" tuvo como objetivo acercar la Institución y la comunidad al Campus Piúma para compartir conocimientos diversos contenidos en el conocimiento de esta comunidad, con el fin de promover la educación, el respeto al saber popular, la formación diversificada y la apreciación de la cultura local. y buenas habilidades interpersonales, discutiendo valores y prácticas, además de desarrollar conocimientos en diversas áreas derivadas de las experiencias de personas de la comunidad externa del Instituto y de la propia práctica educativa de la Institución.

Palabras llave: Extensión. Conocimiento popular y conocimiento académico. Diálogo de conocimiento.

Submetido em: dezembro de 2020.

Aprovado em: janeiro de 2020.

Publicado em: janeiro de 2021. 